\title{
Acute airway management in the emergency department by non-anesthesiologists
}

\section{[L'assistance respiratoire immédiate réalisée à l'urgence par des non-anesthésiologistes]}

George Kovacs MD MHPE FrCPC, J. Adam Law MD FRCPC, John Ross MD FRCPC, John Tallon MD FRCPC, Kirk MacQuarrie MD FrCPC, Dave Petrie MD FRCPC, Sam Campbell MB BCH CCFP(EM), Chris Soder MD FRCPC

Purpose: The responsibility of acute airway management often falls into the hands of non-anesthesiologists. Emergency physicians now routinely use neuromuscular blockade to facilitate intubation. The literature in support of this practice has almost exclusively been published in emergency medicine (EM) journals. This body of literature is presented and issues of educational support are discussed.

Source: A narrative review of the literature on the practice of airway management by non-anesthesiologists.

Principal findings: A significant proportion of acute airway management occurring outside the operating room is being performed by non-anesthesiologists. Rapid sequence intubation (RSI) is recognized as a core procedure within the domain of EM. RSI is being performed routinely by emergency physicians practicing in larger centres. Anesthesiologist support for the practice of RSI by nonanesthesiologists has been weak. Formal educational support outside of postgraduate training in the form of dedicated programs for advanced airway management are now being offered. The majority of the literature on the use of RSI by non-anesthesiologists represents retrospective case series, observational studies and registry data published in EM journals. The reported success rates for RSI performed by non-anesthesiologists is high. Complication rates are significant, however reporting consistency has been poor.

Conclusions: The role of non-anesthesiologists in acute airway management is significant. Despite shortcomings in methodology, current evidence and practice supports the use of RSI by trained emergency physicians. Constructive collaborative efforts between anesthesiology and EM need to occur to ensure that educational needs are met and that competent airway management is provided.
Objectif : La responsabilité de l'assistance respiratoire d'urgence revient souvent à des médecins non-anesthésiologistes. Les urgentistes utilisent maintenant de routine le bloc neuromusculaire pour faciliter l'intubation. La documentation à l'appui de cette pratique a été publiée presque exclusivement dans les journaux de médecine d'urgence $(\mathrm{MU})$. Nous présentons l'ensemble de ces documents et exposons les questions de formation.

Source: Une revue traditionnelle de la documentation sur la pratique de l'assistance respiratoire par des non-anesthésiologistes.

Constatations principales : Une proportion significative de l'assistance respiratoire d'urgence, réalisée à l'extérieur de la salle d'opération, relève de non-anesthésiologistes. L'intubation en séquence rapide (ISR) est reconnue comme une intervention centrale dans le domaine de la MU. L'ISR est généralement réalisée par des urgentistes dans les grands centres. Le soutien anesthésiologique pour la pratique de I'ISR par des non-anesthésiologistes est plutôt faible. Un soutien éducatif formel en dehors de la formation de spécialiste, par des programmes dédiés à l'assistance respiratoires avancée, est maintenant offert. La majorité des publications sur l'usage de l'ISR par des non-anesthésiologistes consiste en séries rétrospectives, études par observation et enregistrement de données publiées dans des journaux de MU. Les taux de succès rapportés pour l'ISR réalisée par des non-anesthésiologistes y sont élevés. Les taux de complications sont significatifs, quoique la cohérence des rapports laisse à désirer.

Conclusion : Le rôle des non-anesthésiologistes dans l'assistance respiratoire immédiate est significatif. Malgré des défauts de méthodologie, les preuves actuelles et la pratique appuient l'usage de I'ISR par des urgentistes formés. Des efforts de collaboration constructive entre l'anesthésiologie et la MU sont nécessaires pour répondre aux besoins éducationnels et assurer la compétence en assistance respiratoire.

From the Departments of Emergency Medicine and Anesthesia, Dalhousie University, Halifax, Nova Scotia, Canada. Address correspondence to: Dr. George Kovacs, 3021 Halifax Infirmary, QEII Health Sciences Centre, 1796 Summer Street, Halifax, Nova Scotia B3H 3A7, Canada. Phone: 902-473-3566; Fax: 902-473-3617; E-mail: gkovacs@dal.ca

All authors are part of the Airway Interventions and Management Education (AIME®) Program Development Group. Accepted for publication March 10, 2003.

Revision accepted July 4, 2003. 
$\mathrm{F}$ EW skills define an anesthesiologist more than the ability to assess and effectively deal with a patient's airway. Obviously most airway management by anesthesiologists occurs in the operating room, however anesthesiologists are also called to other hospital locations to deal with airways, sometimes after other practitioners have failed. All physicians with acute care responsibilities are expected to be reasonably competent in airway management, notably emergency physicians (EPs), intensivists, family physicians, and more. In particular, patient acuity and personnel availability have mandated that physicians working in the emergency department (ED) have the skill to manage a full spectrum of airway problems. As EPs have increasingly taken over this role from anesthesiologists, they have also introduced the use of rapid-sequence induction/intubation (RSI) to the ED.

Despite methodology issues, the emergency medicine (EM) literature supports this practice. This literature and a number of airway courses (e.g., the U.S. based Airway Course ${ }^{\circledR}$ and the Canadian-based Airway Interventions and Management Education Program - AIME®) suggest RSI be considered the default method of intubation unless a contraindication precludes it. In the U.S. and Canada, EP manage the vast majority of patients requiring emergency intubation $^{1-7}$ and, in most of these centres, neuromuscular blocking agents (NMBAs) are used to facilitate intubation as part of a rapid-sequence intubation. . $^{1,3-6,8}$ This practice has raised some concern in the anesthesia community. However, to date, there has been no review in the anesthesia literature on the current state of the published evidence on the use of RSI by nonanesthesiologists.

\section{Background}

In the past, before EDs were staffed by full time personnel, airway management was often limited to orotracheal intubation in the cardiac arrest patient. Anesthesiologists were frequently summoned to the ED for any patient requiring intubation who was breathing spontaneously. In the late 1970's and early 1980 's, EP began to take over this function, often using a blind nasotracheal approach. It was also around this time that reports began to appear in the emergency literature about the use of RSI in the ED. ${ }^{8,9}$ These reports of neuromuscular blockade use in the ED have been almost exclusively published in the EM literature. ${ }^{8-13}$ These publications continue to generate letters of concern over issues of safety. ${ }^{14-17}$ Over the years, in the face of ongoing resistance from groups such as anesthesia over using NMBAs, the practice of using deep sedation to facilitate intubation evolved. On hospital wards, in EDs and in the prehospital setting patients requiring intubation have and are being managed with large (often induction) doses of sedative/induction medications, muscle, and a steel blade (often termed "brutane"). This use of sedation without paralysis, although never formally supported in the literature or any textbook had become a compromise which was perceived as safer through not "burning any bridges." Clearly the onus was on EM to demonstrate that RSI was safer than this compromise approach.

\section{Airway training: how much is enough?}

Much of the concern over the use of muscle relaxants by non-anesthesiologists is based on training and volume. No group of physicians would ever argue that they manage more airways than their anesthesiology colleagues. EPs on the other hand, claim that despite differences in total airway case volume, all patients presenting in the ED are acutely ill and represent a distinctly different population. ${ }^{17,18}$ These differences have even created new terminology. In EM the term RSI refers to rapid sequence intubation. This subtle difference in semantics is meant to represent a different endpoint: in the operating room, patients are intubated to provide anesthesia while in the ED patients are anesthetized/paralyzed to facilitate intubation. ${ }^{19}$

Although these views likely have validity, they also seem to represent turf battles that may be missing the point. Acute airway management should be performed by the person with the greatest experience for that setting. In the operating room that person is the anesthesiologist, in the back of an ambulance it is likely a paramedic, on a hospital ward it may be a respiratory therapist, in the community ED it may be a general practitioner. The method of airway management used by these groups will depend on training and experience. The option of using NMBAs as part of an RSI should therefore depend on these educational issues and not be limited by departmental boundaries. The problem is that this educational context has been lacking. There is a significant difference in the length and sometimes quality of training in airway management between an anesthesiologist and some EP.

In a survey of full and part-time EP conducted by the authors as part of a needs assessment only $16 \%$ reported having learned airway management in undergraduate medicine (Kovacs G, Ross J, unpublished). In the postgraduate setting acute airway management education for non-anesthesia personnel has traditionally been limited to the operating room in an ad-hoc 
manner as part of off-service rotations. Other forms of airway skills learning occur as a subcomponent of programs such as Advanced Trauma Life Support (ATLS) and Advanced Cardiac Life Support (ACLS). Indeed, a number of physicians in this survey listed ATLS and ACLS as their only educational context for having learned airway management. Unfortunately the airway skills portion of programs such as ATLS and ACLS are brief (less than one hour) in duration, are often diluted by other course material and may be taught by inexperienced personnel. These programs have matured over time however and are now providing more cognitive material to support airway management in the acutely ill patient. The most current ACLS document has appropriately emphasized bagvalve mask ventilation, introduced 'intermediate' rescue airways such as the laryngeal mask airway $\left(\mathrm{LMA}^{\mathrm{TM}}\right.$; The Laryngeal Mask Company (UK) Ltd, Henley on Thames, Oxon, UK) and Combitube ${ }^{\mathrm{TM}}$ (Kendall, Mansfield, MA, USA) and stressed the need to objectively confirm tube placement. ${ }^{20}$ The current ATLS program, in turn, has backed away from its previous stance of a "can't intubate cut the neck" airway algorithm and in fact now supports the use of RSI to facilitate airway management in trauma patients. ${ }^{21}$ As a result of ATLS having such a large audience and its acceptance as standard of care, RSI has the potential to be a widely disseminated technique. Unfortunately, the ATLS RSI protocol outlines an approach that recommends succinylcholine without the use of an induction agent. This recommendation is rooted in concerns of hypotension in the volume depleted patient, which admittedly can be devastating, particularly in the head injured patient. However, it is unfortunate that RSI is being introduced to such a large international audience using the rare situation where a NMBA is used without induction.

A second concern of this setting for the introduction of RSI is that it may be perceived as a stand-alone technique. In contrast, more recently introduced programs such as the Airway Course ${ }^{\circledR}$ and the AIME ${ }^{\circledR}$ program take the view that RSI must be learned within a broader and more fluent understanding of airway management, including the importance of examining the airway, bag-valve mask ventilation, aids and adjuncts to direct laryngoscopy, alternative intubation techniques and rescue ventilation techniques. If the clinician is then armed with a solid knowledge of the pharmacology and physiology of the RSI process, has reasonable skills in the technique of direct laryngoscopy, understands the contraindications for the use of neuromuscular blocking drugs, and has an approach to the difficult and failed situation, then the decision to use RSI at the bedside can be entertained. Thus, the major objectives of airway education must include:

1) Recognizing the need for airway management, including intubation.

2) Understanding the indications for and contraindications to RSI, together with when to do an awake intubation.

3) Developing excellent skills in bag-valve mask ventilation and laryngoscopy and intubation (RSI or awake), with an approach to difficulty in each.

4) Developing an approach to the difficult and failed airway.

5) Developing and maintaining the cognitive and psychomotor skills required to competently perform these stated objectives.

The last of the above objectives may be the most difficult to address scientifically due to the paucity of literature on the subject. Specifically, what training is needed to achieve competence in direct laryngoscopy and intubation? Although few studies address this question, a number of operating-room based studies suggest that 50 or more intubations in actual patients are needed to achieve reasonable proficiency in laryngoscopy and intubation. ${ }^{22-25}$

A second and equally important issue then arises: for those personnel who are infrequently involved in acute airway management, skill maintenance becomes a concern. There is evidence that airway skill decay can be minimized by regular practice with expert feedback. ${ }^{26}$ High-fidelity simulation and multi-media programs likely also have a role in both attaining and maintaining airway skill competence. ${ }^{27}$ Simulation has the benefit of being safe and efficient, as well providing the opportunity to adapt to the learner needs and create a 'context of acuity'.

Ultimately, before RSI is added to an individual clinician's armamentarium, significant airway experience must be attained. The 'tissue fidelity' experience achieved by intubating elective surgical patients in the operating room will remain a necessity, regardless of other airway educational efforts. Departments of anesthesia will thus, by definition, be called upon to be involved in this process.

\section{RSI in the ED: what is the current state of evidence?}

There are obvious barriers to the design and implementation of a randomized controlled trial comparing RSI to other methods of intubation in the ED. Consequently, level I evidence is not forthcoming in the literature. However, numerous publications describe various institutions' experiences with RSI. 1,3,4,6,8-13,28-32 
In 1979 Taryle published the first prospective series of ED intubations. ${ }^{32}$ Despite a high (> 50\%) morbidity and mortality rate in these 43 patients, there were no significant differences in complications observed between patients intubated by anesthesia personnel (residents and staff), as compared with ED residents or attending staff. The study was not randomized and the sample size was small. The author commented that "formalizing training" was desirable along with the "more liberal use of the procedures used in the operating room, such as sedation and muscle relaxation." 32 In 1982 Thompson published the first retrospective review of a series of ED intubations facilitated by succinylcholine. ${ }^{8}$ Over the study period, 48 cases out of 820 intubations were intubated using succinylcholine using the indication of decreased level of consciousness accompanied by biting or jaw clenching. Fortytwo of the 48 (87.5\%) were intubated successfully. Six patients had inadequate relaxation, one had transient asystole with the first dose of succinylcholine, and one experienced masseter muscle rigidity. Protocol demanded proceeding to cricothyrotomy with failed intubation, so five patients ultimately received a cricothyrotomy. Despite its use in this series in less than $10 \%$ of cases requiring intubation, RSI began to be claimed by EM as a method of airway management within their domain of practice.

Over subsequent years more case series describing RSI use in the ED were published reporting higher success rates with lower complication/failure rates than originally described. $1,3,4,6,8-13,28-32$ The evidence supporting the use of RSI in the ED has further evolved over the years, coming mainly from prospective observational and retrospective studies (Table).

In 1998 and 2000 Walls et al. published abstracts of results from the National Emergency Airway Registry (NEAR)., ${ }^{1,3}$ This prospective registry represented over 6,000 cases and is the largest series of ED intubation data available to date. Twenty-six teaching hospital sites were involved, the majority from the U.S. RSI was the primary method in $69.5 \%$ followed by no medications in $17.3 \%$, sedation only in $6.8 \%$ and nasal intubation in $5.1 \%$ of cases. The majority of intubations were performed by EPs (adults $88.1 \%$, children $81.1 \%$ ). The overall success rate for intubation was $98.7 \%$ for RSI, $94.9 \%$ with no medications, $90.2 \%$ with sedation and $87.2 \%$ for nasotracheal intubation. A full manuscript explaining the results has not been published, however a likely reason for the high success rates for the 'no medication' group is that they represented end-stage pre- or fully arrested patients. Multiple intubation attempts were required less frequently in the RSI group, but the differences were not as significant as reported previously. An intubation 'event' rate of $15.3 \%$ was reported from this registry. Events were 'technical' in $7.3 \%$, 'physiologic' in $2.9 \%$ and 'immediate complications' in $2.9 \%$. Although the need for multiple attempts at intubation correlates with complication rate, this information was not available for comparison between groups. Overall, the 'immediate complication' rate directly attributable to intubation was 3.5\%.

Li et al. prospectively examined methods of intubation in the three months prior to, and the six months following the implementation of an ED RSI protocol. ${ }^{13}$ They reported significantly fewer complications with RSI (166 patients) compared to intubation without paralysis (67 patients). The reported complication rate was $28 \%$ for the RSI group and $78 \%$ for those intubated without paralysis. In the non-paralyzed group there was a $15 \%$ rate of aspiration, a $28 \%$ rate of airway trauma, and a $3 \%$ death rate. Surprisingly, none of these complications were reported in the RSI group.

Sakles et al. looked at all 610 intubations performed in an urban teaching hospital ED over one year (1995-1996). ${ }^{4}$ Postgraduate year three (PGY3) residents in EM intubated $73.5 \%$ of patients, PGY2s in EM $17.8 \%$ and PGYls 2.6\%. Staff EP intubated $6.2 \%$ of this patient population, often after a failed attempt by the EM resident. The results were similar to that reported in the NEAR registry. In the RSI group there was a 99.4\% success rate. In the sedation/orotracheal intubation (OTI) group the success rate was $91.5 \%$. It is noteworthy that five of the unsuccessful intubations in the OTI group were intubated successfully with RSI. Unfortunately, the complication rates were, again, not broken down according to group. The immediate complication' rate was $9.3 \%$, comprised mainly of desaturation, bronchial intubation and vomiting.

More dramatic differences were reported by Fortney comparing RSI, non-RSI and nasal intubations in an urban teaching ED. RSI required fewer attempts ( 1.1 vs 1.5 and 2.0 respectively), had higher success rates (92\% vs 66\% and 54\%) and fewer complications ( $0 \%$ vs $10 \%$ and $29 \%)$.

Tayal et al. reported very similar numbers with 417 patients undergoing RSI over two years in a single ED. ${ }^{12}$ The majority of intubations were performed by EM residents (97\%). They reported a 96.5\% success rate requiring two or less intubation attempts. Immediate major physiologic events (hypotension, hypoxia or dysrhythmias) occurred in $1.4 \%$ while other adverse events were reported in $14.4 \%$ of cases. No deaths were reported to be attributable to RSI.

In one of the earliest and only papers to actually randomize patients in the ED Dronen et al. reported 
TABLE Airway management in the emergency department

\begin{tabular}{|c|c|c|c|c|c|}
\hline Author & Setting/design & Variables & $R S I$ & Sedation & Nasotracheal \\
\hline \multirow{4}{*}{$\begin{array}{l}\text { Walls, et al. (abstract) } \\
\text { NEAR Registry data } 2000^{1}\end{array}$} & \multirow{4}{*}{$\begin{array}{l}\text { Teaching hospital ED's/ } \\
\text { prospective observational } \\
\text { registry }(n=6294)\end{array}$} & Methods: & $69.5 \%$ & $6.8 \%$ & $5.1 \%$ \\
\hline & & Success: & $98.7 \%$ & $90.2 \%$ & $87.2 \%$ \\
\hline & & Attempts: & $(>3) 2.1 \%$ & $(>3) 10.7 \%$ & $(>3) 14.3 \%$ \\
\hline & & $\begin{array}{l}\text { Complications: } \\
\text { (overall 15.3\%) }\end{array}$ & $\mathrm{NA}$ & NA & NA \\
\hline \multirow[t]{4}{*}{ Li et al. $1999^{13}$} & \multirow{4}{*}{$\begin{array}{l}\text { High volume } \\
\text { tertiary care } \mathrm{ED} / \text { prospective } \\
\text { observational }(n=233)\end{array}$} & Methods: & $71 \%$ & $29 \%$ & \\
\hline & & Success: & $99 \%$ & $72 \%$ & \\
\hline & & Attempts: & $(>3) 2 \%$ & $(>3) 24 \%$ & \\
\hline & & $\begin{array}{l}\text { Complications: } \\
\text { (overall } 42 \% \text { ) }\end{array}$ & $28 \%$ & $78 \%$ & \\
\hline \multirow[t]{4}{*}{ Sakles et al. $1998^{4}$} & \multirow{4}{*}{$\begin{array}{l}\text { High volume } \\
\text { tertiary care } \mathrm{ED} / \text { prospective } \\
\text { observational }(n=610)\end{array}$} & Methods: & $83.4 \%$ & $15.2 \%$ & $1.3 \%$ \\
\hline & & Success: & $99.4 \%$ & $91.4 \%$ & $75 \%$ \\
\hline & & $\begin{array}{l}\text { Attempts: } \\
(\text { overall > 2: } 5.3 \%)\end{array}$ & NA & NA & $\mathrm{NA}$ \\
\hline & & $\begin{array}{l}\text { Complications: } \\
\text { (overall 9.3\%) }\end{array}$ & NA & NA & NA \\
\hline \multirow[t]{4}{*}{ Tayal et al. $1999^{12}$} & \multirow{4}{*}{$\begin{array}{l}\text { Teaching hospital ED/ } \\
\text { prospective observational } \\
(n=596)\end{array}$} & Methods: & $70 \%$ & NA & NA \\
\hline & & Success: & $100 \%$ & NA & NA \\
\hline & & Attempts: & $(>3) 3 \%$ & NA & NA \\
\hline & & Complications: & $15.8 \%$ & NA & NA \\
\hline
\end{tabular}

$\mathrm{ED}=$ emergency department. NEAR $=$ National Emergency Airway Registry.

$100 \%$ success with RSI compared with a $65 \%$ success rate in the blind nasotracheal intubation (BNTI) group. ${ }^{10}$ In the BNTI group $10 \%$ aspirated, $17 \%$ vomited, and $69 \%$ had epistaxis. Of note, the ten failures in the BNTI group were successfully intubated orally using RSI.

In a randomized trial, Collins compared intubating conditions with and without the use of NMBAs. ${ }^{33}$ In the controlled setting of the operating room in healthy (ASA I-II) ambulatory patients induction doses of propofol $\left(2.5 \mathrm{mg} \cdot \mathrm{kg}^{-1}\right)$ were given in combination with a potent narcotic either alone or immediately preceding a dose of a NMBA. Although no difference in successful intubations were noted, "suboptimal intubating conditions" including limb movement, coughing and poor view were described in 37\% of the cases where a NMBA was not used. There was also a higher incidence of vocal cord adduction in this unparalyzed group.

Lieutaud et al. recently compared intubating conditions using varying doses of propofol with or without the use of neuromuscular blockade. ${ }^{34}$ 'Excellent intubating conditions' were achieved in only $35 \%$ of patients receiving propofol alone compared to $95 \%$ in those receiving propofol followed by neuromuscular blockade. Other recent publications have similarly documented that high dose combinations of induction agent and narcotic are required to achieve adequate intubating conditions if no NMBA is used. ${ }^{35,36}$ However, if these doses were used in acutely ill ED patients, catastrophic hypotension (and apnea) could ensue, and intubating conditions may still be suboptimal.

In 1997,15 years after the first published use of succinylcholine in the ED the American College of Emergency medicine issued a policy statement on RSI, which included the following statements: ${ }^{37}$

- Physicians performing RSI should possess training, knowledge, and experience in the techniques and pharmacologic agents used to perform RSI.

- NMBAs and appropriate sedative and induction agents should be immediately available in the ED and accessible to all physicians who perform RSI in the ED.

- Quality review and patient monitoring should be addressed when policies about RSI are developed in the ED.

There is little published on the use of RSI outside of teaching centres. Dufour and colleagues looked at their experience with RSI in a community ED. In 219 intubations, no mortality was attributed to the use of a NMBA, and the most frequent complication was 
transient hypotension responding to simple measures. No patient required an alternative technique to control the airway. ${ }^{11}$

\section{Discussion}

Despite inconsistencies in design and reporting, published data demonstrate that with RSI in the ED, the chances of successful intubation are higher and the complication rate is lower when compared with other methods. However a few cautions are noteworthy when examining this literature. First, the most commonly reported outcome measures of successful intubation and complications are only surrogate markers of patient outcome. We still do not know whether RSI results in better patient outcomes when compared with other methods. The reporting of complications in this literature is not consistent and data that would allow comparisons between methods of intubation are missing. Without this comparative information, the reported numbers of major physiologically significant complications are difficult to interpret. Second, since most of these data come from large volume tertiary care centres, it may be difficult to generalize to the community setting. Finally some of the patient data have only been published in abstract form, therefore limiting the ability to critically appraise the results.

One additional note is that in many of the studies quoted above, the fallback method of securing the airway once direct laryngoscopy had failed was cricothyrotomy. Little mention was made of adjunctive maneuvers and equipment such as external laryngeal manipulation and the gum elastic bougie respectively, nor of alternative intubation techniques such as the lightwand or intubating LMA. Similarly, use of rescue ventilation devices such as the $\mathrm{LMA}^{\mathrm{TM}}$ or Combitube ${ }^{\mathrm{TM}}$ is rarely mentioned. Although laryngoscopy and intubation success rates may be high following RSI in the ED, other issues must still be addressed. Training in and availability of adjuncts, alternative intubation techniques and rescue ventilation devices is a necessity.

Finally, EPs must have a clear and consistent approach to unanticipated difficult and failed airway situations. Ultimately, airway management can occur without RSI, however the reverse is not true. RSI cannot proceed without a broad skill and approach to airway management.

\section{Conclusion}

RSI has become an EM procedure for airway management. The emergency literature, despite limitations of methodology and reporting, supports the use of RSI in the hands of EP in that decreased morbidity has been described with its use. The educational support that provides the answers to when and (importantly) when not to use RSI, and what to do if things go wrong is being addressed in a formal manner with courses such as the Airway Course ${ }^{\circledR}$ and the AIME ${ }^{\circledR}$ program. However, this must be complemented with teaching and experience in actual patients, and must involve the operating room. Anesthesiologists should be aware of this phenomenon and be prepared to respond to requests for involvement in the education and maintenance of airway skill competence of nonanesthesiologists.

\section{Acknowledgements}

Canadian Association of Emergency Physicians (CAEP) for their support in the development of the AIME program.

\section{References}

1 Walls RM, Gurr DE, Kulkarni RG, Sakles J, Pollack C. 6,294 emergency department intubations: second report of the ongoing National Emergency Airway Registry (NEAR) II Study. Ann Emerg Med 2000; 36: S51.

2 Gaspari R, Singer AJ. Emergency intubations: where and by whom? Ann Emerg Med 2000; 36: S51.

3 Walls RM, Vissers RJ, Sagarin MJ, et al. 2392 emergency department intubations: first report of the ongoing national airway registry (NEAR 97) study. Acad Emerg Med 1998; 5: 393.

4 Sakles JC, Laurin EG, Rantapaa AA, Panacek EA. Airway management in the emergency department: a one-year study of 610 tracheal intubations. Ann Emerg Med 1998; 31: 325-32.

5 Nayyar P, Lisbon A. Non-operating room emergency airway management and endotracheal intubation practices: a survey of anesthesiology program directors. Anesth Analg 1997; 85: 62-8.

6 Ma OJ, Bentley B II, Debehnke DJ. Airway management practices in emergency medicine residencies. Am J Emerg Med 1995; 13: 501-4.

7 Gallagher EJ, Coffey J, Lombardi G, Saef S. Emergency procedures important to the training of emergency medicine residents: who performs them in the emergency department? Acad Emerg Med 1995; 2: 630-3.

8 Thompson JD, Fish S, Ruiz E. Succinylcholine for endotracheal intubation. Ann Emerg Med 1982; 11: 526-9.

9 Roberts DJ, Clinton JE, Ruiz E. Neuromuscular blockade for critical patients in the emergency department. Ann Emerg Med 1986; 15: 152-6.

10 Dronen SC, Merigian KS, Hedges JR, Hoekstra JW, Borron $S W$. A comparison of blind nasotracheal and succinylcholine-assisted intubation in the poisoned patient. Ann Emerg Med 1987; 16: 650-2. 
11 Dufour DG, Larose DL, Clement SC. Rapid sequence intubation in the emergency department. J Emerg Med 1995; 13: 705-10.

12 Tayal VS, Riggs RW, Marx JA, Tomaszewski CA, Schneider RE. Rapid-sequence intubation at an emergency medicine residency: success rate and adverse events during a two-year period. Acad Emerg Med 1999; 6: 31-7.

13 Li J, Murphy-Lavoie H, Bugas C, Martinez J, Preston C. Complications of emergency intubation with and without paralysis. Am J Emerg Med 1999; 17: 141-4.

14 Cheng EY, Nimphius N, Kampine JP. Anesthetic drugs and emergency departments. Anesth Analg 1992; 74: 272-5.

15 Berry J. Airway management in the emergency department (Letter). Br J Anaesth 2002; 88: 876-7; discussion 878-9.

16 Taylor IR. Anaesthetic training for trainees in accident and emergency medicine (Letter). Anaesthesia 2000; 55: 302.

17 Graham CA, Munro PT. Airway management in the accident and emergency department (Letter). Anaesthesia 2000; 55: 814.

18 Nolan J, Clancy M. Airway management in the emergency department (Editorial). Br J Anaesth 2002; 88: 9-11.

19 Dronen S. Rapid-sequence intubation: a safe but illdefined procedure. Acad Emerg Med 1999; 6: 1-2.

20 ECC Guidelines. Part 6: advanced cardiovascular life support. Section 7: algorithm approach to ACLS emergencies. 7A: principles and practice of ACLS. The American Heart Association in collaboration with the International Liaison Committee on Resuscitation. Circulation 2000; 102(Suppl): I-136-65.

21 Subcommittee on Advanced Trauma Life Support of the American College of Surgeons. Advanced Trauma Life Support, 6th ed. First Impressions, 1997.

22 de Oliveira Filho GR. The construction of learning curves for basic skills in anesthetic procedures: an application for the cumulative sum method. Anesth Analg 2002; 95: 411-6.

23 Charuluxananan S, Kyokong O, Somboonviboon W, Pothimamaka $S$. Learning manual skills in spinal anesthesia and orotracheal intubation: is there any recommended number of cases for anesthesia residency training program? J Med Assoc Thai 2001; 84 (Suppl 1): S251-5.

24 Konrad C, Schupfer G, Wietlisbach M, Gerber $H$. Learning manual skills in anesthesiology: is there a recommended number of cases for anesthetic procedures? Anesth Analg 1998; 86: 635-9.

25 Mulcaster JT, Mills J, Hung OR, et al. Laryngoscopic intubation. Learning and performance. Anesthesiology
2003; 98: 23-7.

26 Kovacs G, Bullock G, Ackroyd-Stolarz S, Cain E, Petrie $D$. A randomized controlled trial on the effect of educational interventions in promoting airway management skill maintenance. Ann Emerg Med 2000; 36: 301-9.

27 Levitan RM, Goldman TS, Bryan DA, Shofer F, Herlich $A$. Training with video imaging improves the initial intubation success rates of paramedic trainees in an operating room setting. Ann Emerg Med 2001; 37: 46-50.

28 Talucci RC, Shaikh KA, Schwab CW. Rapid sequence induction with oral endotracheal intubation in the multiply injured patient. Am Surg 1988; 54: 185-7.

29 Rotondo MF, McGonigal MD, Schwab CW, Kauder DR, Hanson $C W$. Urgent paralysis and intubation of trauma patients: is it safe? J Trauma 1993; 34: 242-6.

30 Vijayakumar E, Bosscher H, Renzi FP, Baker S, Heard $S O$. The use of neuromuscular blocking agents in the emergency department to facilitate tracheal intubation in the trauma patient: help or hindrance? J Crit Care 1998; 13: 1-6.

31 Butler JM, Clancy M, Robinson N, Driscoll P. An observational survey of emergency department rapid sequence intubation. Emerg Med J 2001; 18: 343-8.

32 Taryle DA, Chandler JE, Good JT Jr, Potts DE, Sahn $S A$. Emergency room intubations-complications and survival. Chest 1979; 75: 541-3.

33 Collins L, Prentice J, Vaghadia H. Tracheal intubation of outpatients with and without muscle relaxants. Can J Anesth 2000; 47: 427-32.

34 Lieutaud T, Billard V, Khalaf H, Debaene B. Muscle relaxation and increasing doses of propofol improve intubating conditions. Can J Anesth 2003; 50: 121-6.

35 Erhan E, Ugur G, Gunusen I, Alper I, Ozyar B. Propofol - not thiopental or etomidate - with remifentanil provides adequate intubating conditions in the absence of neuromuscular blockade. Can J Anesth 2003; 50: 108-15.

36 Jabbour-Khoury SI, Dabbous AS, Rizk LB, et al. A combination of alfentanil-lidocaine-propofol provides better intubating conditions than fentanyl-lidocaine-propofol in the absence of muscle relaxants. Can J Anesth 2003; 50: 116-20.

37 American College of Emergency Physicians. Rapidsequence intubation. Ann Emerg Med 1997; 29: 573. 